\title{
THE EXPRESSIONS OF EXCLAMATION: A CROSS- CULTURAL ANALYSIS IN AUSTRALIAN ENGLISH AND BAHASA INDONESIA
}

\author{
Adrefiza \\ (adref64@yahoo.co.id) \\ Jambi University
}

\begin{abstract}
This study investigated and compared exclamatory expressions performed by native speakers of Australian English and Bahasa Indonesia. Three different contexts and situations were selected as the prompts for the respondents to express their exclamations: (a) surprise; (b) enthusiasm; and (c) annoyance. Based on data from 36 respondents of both languages, the findings revealed that both Australian English and Bahasa Indonesia were likely to utilize different types of exclamatory words, phrases or expressions of surprise, enthusiastic and annoyance. Te expressions seemed to be systematic in their constructions and the selection of words or phrases remained personal and indicated the speakers' feeling, attitude, and emotion. In expressing surprise and enthusiasm, in particular, the selection of words or phrases by both language communities tended to use positive and socially acceptable exclamatory expressions. However, when they turned to express annoyance, most of the words, phrases, or expressions used were often taboo and socially unacceptable.
\end{abstract}

Key Words: exclamation, australian English, bahasa Indonesia, cultural analysis

\section{INTRODUCTION}

Exclamation is inevitably frequent in our society. It is an evidence of a reflection of the speaker's emotion and feeling. Its use and realization may differ considerably from language to language and from culture to culture, whether pragmatically or sociolinguistically. When there are differences and similarities across cultures in its use, they are often 
peculiar and unpredictable. It is, therefore, obvious when many pragmatic scholars claim that exclamation is a unique characteristic of a particular culture (see Wierzbicka, 1991). A universal view, however, is that the consciousness of the use of exclamation is very much associated with personal character of the exclaimer as well as the context and situation in which it occurs. Basically, in order for an exclamation to occur, the exclaimer must have something to feel or to want or at least something to share with the hearers. Although there is likely no exact evidence to predict what one really feels through exclamation, psychological and pragmatic analysis may be helpful to do so.

This research project paper, consequently, was trying to investigate the realization of exclamation in Australian English and Bahasa Indonesia and see if there was any cultural relevance between them. The analysis focused on the use of exclamation or interjection in expressing surprise, enthusiasm, and annoyance. Age and gender of the exclaimers were included to see if there were any differences in its use according to these aspects.

\section{THEORETICAL FRAMEWORK Concept of Exclamation/Interjec- tion}

Drazdauskiene (1981, p.56) points out, "stereotypically, exclamations express enthusiastic appreciation for something which the speaker presumed to be shared by the addressee. They often sound exaggerated and insincere, and they certainly don't sound dogmatic". From Drazdauskiene's point of view, it is apparent that exclamation occurs as a reflection of what one feels - very enthusiastically and exaggeratedly. It does not express the speaker's belief or opinion. At the same time, the speaker attempts to share what $\mathrm{s} /$ he feels with the hearer.

The terms exclamation and interjection have frequently been defined interchangeably. Both refer 
to linguistic signs which express a specifiable meaning. They both indicate and express a strong feeling or emotion of the speaker. Wierzbicka (1991) distinguishes them in terms of complexity and felicity condition of the expressions. She views that exclamation is somewhat more felicitous and involves more complex expression, while interjection tend to be simpler. To make the distinction clear, she provides a few examples such as; Oops!, Ouch!, Wow! (interjections) and How nice!, What a woman! (Exclamations). It seems that from these examples, exclamation is more global and elaborate than interjection. It contains a longer construction involving more words or phrases.

In more details, Wierzbicka (1991, p.290) defines the concept of interjection as "a linguistic sign (1) which can be used as its own, (2) which expresses a specifiable meaning, (3) which does not include other signs (with a specifiable meaning), (4) which is not homophonous with another lexical item that would be perceived as semantically related to it, and (5) which refers to the speaker's current mental state or mental act". Based on these characteristics, Wierzbicka, then, suggests that exclamations such as Good Lord!, Good heavens!, Christ!, or Hell! are not interjections, whereas those like gee, wow, oops, or ha are apart from above distinction. The present study, however, uses both combinations to mean the expressions of exclamation.

\section{The Use of Interjection/Exclamation}

Wierzbicka (1991) claims that interjections, in fact, require the combinations of culture-specific conventions and universal 'laws of nature'. Generally speaking, according to Wierzbicka, interjections often show outstanding similarities across language and culture limits, but these similarities are often unpredictable and have to be learnt just as much as the differences. It may also be evident that there are 
no similarities across language and culture at all.

The use of interjections is, in fact, unique. As suggested by Wierzbicka (1991), it is hard to guess what they mean and how they are to be used. Although dictionaries usually give information of the unpredictability and conventional characters of interjections, they could hardly clarify how to attach and use them in a normal life situation. LDOTEL (as cited in Wierzbicka, 1991) provides the use of several interjections in English. According to LDOTEL, wow is used to express strong feeling such as pleasure and surprise, gee is used to express surprise or enthusiasm, ah is used to express delight, relief, regret, or contempt, and phew is used to express relief, amazement or exhaustion. However, in everyday life, it is obvious that such expressions are frequently used interchangeably and they often reveal no difference in their use at all. Thus, as Wierzbicka (1991) suggests, in order to have a better understanding of the use of interjections one should have prolonged immersion in the environment in which the language is spoken.

\section{Lingustic Forms of Exclamations}

Drazdauskiene (1981) asserts that exclamations can take a number of forms such as: affirmative, interrogative, negative, and negative-interrogative. In English, he claims, exclamations can take not only an affirmative and positive form, as in How nice!, but also an interrogative-negative one, as the utterance: Isn't it marvelous! Or in the form of tag questions such as, Terrible place, isn't it? It is obvious that the tag question forms do not use interjection mark but question mark instead. This may be used simply to express the speaker's feeling and often to seek agreement or confirmation from the hearer or addressee about what is being exclaimed and shared by the exclaimer. To some extent, it can also be used as a strategy to open a 
conversation as the expression requires the hearer to respond to it. When tag question forms are used, the speaker is, in fact, trying to be indirect in his/her remarks without reducing the importance of the meaning of the expressions. Such expressions are frequently regarded as the language of feminism as they are commonly used by females in their conversations (see Wardhaugh \& Drazdauskiene in Wierzbicka, 1991).

In terms of meanings conveyed by interjections, Wierzbicka (1991) classifies interjections into three types. The classification is associated with the exact nature of the speaker's mental states when performing them. They are: (1) emotive (those which have in their meaning the component "I feel something "); (2) volitive (those which have in their meaning the component "I want something"); (3) cognitive (those which have in their meaning the component "I think something" or "I know something") (see Wierzbicka, 1991:
291). From this classification, however, such distinct meanings may be frequently interpreted interchangeably in their real use. Here, context and situation as well as the topic of exclamation play an important role in interpreting what an interjection actually means. In addition, the intonation markers may frequently remain influential as well. Expressions like "Wow!" or "Aha!", for example, may represent emotive or volitive and cognitive depending on in which context or situation they are performed. Pragmatically, they may mean many things but semantically, they may not mean anything.

The choice of words in exclamations, to some extent, may indicate the speaker's attitude. Some exclamatory words or expressions can have a strong connotation and a very sensitive meaning. These expressions occurs usually when the speaker is out of control or in a bad mode, such as in feeling annoyance, disgusted, stress, or a great anger. According to Anderson \& Trudgill (1990), 
people swear (using bad or taboo expressions) when they are shocked or appalled. Montagu (1967) claims that swearing words are frequently related to sensitive, excrement, or blasphemous notion like: damn!, Christ!, bloody (hell)!, bugger!, shit!, Damn it!, etc. In more details, he classifies the words and phrases used in expressing annoyance (swearing) as words which refer to:

(a) names of supernatural or infernal power, of gods, angels, and devils (Crist!, Jesus! etc); (b) names connected to sacred matters of religion (God's blood!) and future life (Heavens!, Hell!, Damn!,).

\section{METHODS \\ Sample}

The study was conducted in Canberra involving 36 native speakers of Australian English and Bahasa Indonesia. They were selected accidentally on the basis of mutual convenience between the researcher and the participants. The number of the sample and the way how they were selected accidentally rather than randomly, is merely subject to the limitation of the study such as the time constraints and the scope of the study. This Follows Yuan (2001), who claims that the selection of the participants should be based on researcher's personal judgment (judgment sampling method). This is supposed to maximize the validity of the study (Johnson, cited in Yuan 2001). This procedure has also been applied by Milroy (cited in Yuan, 2006). The following table summarizes the distribution of the sample.

Table 1

\section{Sample Distribution}

\begin{tabular}{cccccc}
\hline Age & \multicolumn{2}{c}{ Australians } & \multicolumn{2}{c}{ Indonesians } & Total \\
& Male & Female & Male & Female & \\
$<25$ & 3 & 3 & 3 & 3 & 12 \\
$26-35$ & 3 & 3 & 3 & 3 & 12 \\
$>36$ & 3 & 3 & 3 & 3 & 12 \\
Total & 9 & 9 & 9 & 9 & 36 \\
\hline
\end{tabular}

\section{Data Collection}

There has been a number of data collection techniques used in pragmatics studies. Some of them, according to Gollato (2003), include: Naturally Occurring 
Conversation

Recordings;

Discourse Completion Tasks (DCTs); Completion Questionnaires; Taped-Role Plays; Field Observations; and Recall Protocols. Houck and Gass (1996) assert that it is not yet precisely known to what extent differences in data collection methods account for differences in results. Therefore, prior studies have attempted to employ variety of techniques in investigating a particular speech act (Kohler 2008; Tran 2008). It appears that each technique has its own strengths and drawbacks. Thus, its selection should match the study types and aims.

The present study employed A DCTs in collecting data. For Australians, questionnaire was written in English and for Indonesians it was written in Bahasa Indonesia. Ideally, the data collected should be natural by means of which the exclamations occur in natural situations - spoken rather than written in questionnaire. However, again, based on the study limitation, such data was not feasible. DCTs have been frequently used as an alternative technique in pragmatics studies. As suggested by Wouk (2006), the majority of crosscultural pragmatic data have been based on a DCT. She defines DCT as a form of questionnaire in which situations are described and respondents are asked what they would say in those situations. Tran (2008, p.2) remarks, “In a DCT, a number of situations are described in writing with spaces for research participants to fill in what they would say in such situations". Although DCTs have been criticized in terms of their authenticity due to their failure to represent natural speech data, they have long been employed successfully by many prominent socio-pragmatic scholars, including Blum-Kulka and Olshtain (1989) in their CCSARP project. Another significant advantage is simply concerned with the relatively high degree of control that the researchers can establish over a few selected social variables such age, 
gender, situation, role relationships, and power status of the interactants (Tran, 2008; Golato, 2003) and thus the study can easily be further replicated.

The content of the questionnaire was divided into three sections: (A) expressing surprise, (B) expressing enthusiasm, and (C) expressing annoyance. Each section consisted of 6 completion questions through which the speaker expressed the exclamations or interjections. The division of the sections (A), (B), and $(C)$, and also the identified situations, were merely based on common social events in which the exclamations or interjections normally occur. Age and gender of the participants were included in the questionnaire.

\section{Data Analysis}

All exclamatory expressions of surprise, enthusiasm, and annoyance were noted down, grouped, calculated, and analyzed according to gender and the age of the speakers. Age variable was divided into three categories:
(A) below 25, (B) 26 - 35, and (C) above 36. Gender variable was included in the age category division - thus, each category A, B, and $C$ had both Male and Female divisions. This division was intended to see if there was any difference of the expressions or exclamatory words or phrases used according the above categories. Basically, the study analyzed three main aspects; (1) exclamatory words/phrases/expressions; (2) lexical constructions (forms) of the expressions; and (3) pragmatic meaning of the expressions.

\section{FINDINGS AND DISCUSSION}

It appeared that both Australians and Indonesians had different sets of exclamatory words/phrases/expressions. They occurred unpredictably but seemed to be systematic in their forms or constructions. Both languages had several common exclamatory words - most of them were not phonologically and semantically similar. However, there were a few exclamatory words which 
appeared in both languages. These words were such as: "Ah!", "Hei!", "Ha?", "Eh!", and "Hi!". These words occurred mostly in expressing surprise, especially when someone met a friend whom she/he has never met for a long time.

In expressing surprise, the words or phrases "Great!" or "This is (just) great!", "Wow!", "Well done!", appeared very frequently in Australian English (15 times). In addition, "Congratulations!", "Incredible (Unbelievable)!", "Marvellous!", and "Fantastic!", were also frequent. In general, there were no noticeable differences in the word selections according to gender of the speakers. However, phrases like: "Well done!" and "Fantastic!" seemed to be used more frequently by females. In addition, there were a few phrases which only occurred in females' expressions. Such expressions were as: "Gee!", "What up dude!", "Oh my God!", "Yeaww!", and "Good Heavens!". The occurrence of these expressions seemed to be unpredictable. In other words, there were no reasons which accounted for their occurrence in females' expressions. Quite often, in real situation, there were no indications of whether they were preferable to males or females only. In Bahasa Indonesia, on the other hand, the words or phrases "Aduh!" or "Duh!" or “Waduh", "Masa (iya)?", "Hebat!", and "Luar biasa!" were very common in expressing surprise. Most of the expressions were used by both males and females. "Masa (iya)?" (really?) tended to appear more in males' expressions. Furthermore, phrases like: "Amboi!" (Wow!) and "Bukan main!" (Incredible!") did not occur in females' expressions. Table 2 below provides information about the exclamatory words or phrases used in expressing surprise in both languages.

IJEE, Vol. 1, No. 1, 2014 |9 
Table 2

Exclamatory Words or Phrases Used in Expressing Surprise

\begin{tabular}{|c|c|c|c|c|c|c|c|c|}
\hline \multirow{2}{*}{ Australian English } & \multicolumn{3}{|c|}{ Freq. } & \multirow{2}{*}{ Bahasa Indonesia } & \multicolumn{4}{|c|}{ Freq. } \\
\hline & $\mathrm{F}:$ & 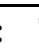 & & & F : & $\overline{\bar{M}}$ & : Tot & \\
\hline (This is) (just) Great! & & & & Aduh! & & & & \\
\hline Wow! & 8 & 7 & 15 & (Waduh!) & 6 & & 7 & 13 \\
\hline Well done! & 6 & 6 & 8 & Gila! & - & & 3 & 3 \\
\hline Congratulations! & 6 & 2 & 7 & Masa (iya)! & 5 & & 1 & 6 \\
\hline Incredible! & 4 & 3 & & Buset! & 1 & & 2 & 3 \\
\hline (Unbelievable!) & & & 6 & Ya ampun! & 1 & & 1 & 2 \\
\hline Marvellous! & 3 & 3 & 5 & Amboi! & - & & 1 & 1 \\
\hline Fantastic! & 2 & 3 & 4 & Hei! & 2 & & 1 & 3 \\
\hline Gee! & 3 & 1 & 1 & Hebat (ya)! & 2 & & 3 & 5 \\
\hline Wonderful! & 1 & - & 2 & Selamat (ya)! & 3 & & 1 & 4 \\
\hline Awesome! & 1 & 1 & 1 & Luar biasa! & 1 & & 3 & 4 \\
\hline What up dude! & - & 1 & 1 & Asyik! & 1 & & 1 & 2 \\
\hline Oh my God! & 1 & - & 1 & Bukan main! & - & & 2 & 2 \\
\hline Hi! (Hey!) & 1 & - & 3 & Ah (Wah) (Eh), & & & & \\
\hline Yeaww! & 1 & 2 & 1 & tumben! & 3 & & 2 & 5 \\
\hline Good Heavens! & 1 & - & 1 & Combination: & & & & \\
\hline Combination: Wow! & 1 & - & 3 & Waduh, hebat ya? & & & 2 & 3 \\
\hline Well done! & 1 & 2 & 2 & Hebat, selamat & 2 & & & \\
\hline Wow, incredible! & 1 & 1 & & ya? & & & 3 & 5 \\
\hline
\end{tabular}

It was also evident in the table above that there were expressions, either in Australian English or in Bahasa Indonesia, which consisted of more than one exclamatory word. Expressions such as "Wow, incredible!" or "Wow, well done!", for example, occurred sometimes in Australian English. While "Waduh, hebat ya?" and "Hebat, selamat ya?" occurred frequently in Bahasa Indonesia. These expressions were, basically, used when the speaker felt surprise to somebody who has done something good or something different from what $s /$ he has usually done/had before. Such expressions might also indicate the strong feeling of the speaker. They might also be used to strengthen the speaker's feeling or emotion.

Many of the above exclamatory words/phrases/expressions also occurred in expressing enthusiasm. As can be seen in Table 3 below, words such as; "Great!", 
"incredible!", "Fantastic!", and "Marvellous!" were also used in expressing enthusiasm by Australians. Again, in general, there seemed to be no noticeable association in the word or phrase selections according to gender of the exclaimers, although "Great! (I can't wait) appeared more frequently in females' expressions. Expressions like: "I'm really thrilled" and "Well, what exciting things" only occurred in females' expressions. Again, it was likely that, the occurrence of such expressions were unpredictable. It was also apparent that the word "Thanks" occurred as exclamatory expressions of enthusiasm in Australian English. This word occurred, basically, when the speaker received a good news and it made him/her very enthusiastic. Thus, the word "Thanks" was used to indicate the speaker's happiness and thankfulness. In Bahasa Indonesia, "Nah!" or "Nah (ini) gitu dong!", "Alhamdulillah", "Masa (iya)?" were often used in expressing enthusiasm. In general, there were no association in their use according to gender and the age of the speakers. However, phrases like: "Betul juga perasaan saya" (That's what I thought), "Asyik!" (no exact synonym in English) and "Bukan main!" (Incredible) occurred only in males' expressions.

Like "Thanks" in Australian English, the word "Alhamdulillah" (religious words, means "Prays to God" or "Thanks Godness") was also used in Bahasa Indonesia. It was as an evidence of the speakers' thankfulness to the God or as a reflection of their happiness, especially when receiving good news. It appeared that, such a word was frequently used by the older exclaimers (mostly by the speakers of above 36 years old). The use of "Alhamdulillah" could be seen as an evidence of the religious awareness of the Indonesian society. Table 3 below provides information about types and frequency of the exclamatory words/phrases / expressions of enthusiasm in both languages. 
Table 3

Exclamatory Words or Phrases Used in Expressing Enthusiasm

\begin{tabular}{|c|c|c|c|c|c|c|c|}
\hline \multirow[t]{2}{*}{ Australian English } & \multicolumn{3}{|c|}{ Freq. } & \multirow[t]{2}{*}{ Bahasa Indonesia } & \multicolumn{3}{|c|}{ Freq. } \\
\hline & \multicolumn{3}{|c|}{ F:M :Tot } & & F : & M : & \\
\hline Great! (I can't wait to go) & 5 & 3 & 8 & Nah (ini) (gitu dong)! & 3 & 3 & 6 \\
\hline Incredible! (Unbelievable!) I & 3 & 3 & 6 & Wah, dari dulu dong! & 1 & 2 & 3 \\
\hline can' believe this! & & & & Masa (iya)! & 2 & 2 & 4 \\
\hline Marvellous! & 2 & 2 & 4 & Duh! Ini yang ditunggu- & & & \\
\hline Fantastic! & 2 & 2 & 4 & tunggu! & 2 & 1 & 3 \\
\hline Gee! & 3 & 1 & 4 & Ya ampun! & 1 & 1 & 2 \\
\hline Thanks & 3 & 2 & 5 & Hebat dong saya! & 1 & 1 & 2 \\
\hline Wonderful! & 2 & 1 & 3 & Ah, yang benar aja? & 1 & - & 1 \\
\hline (Wow!) Good news! & 1 & 3 & 4 & Betul juga perasaan saya! & - & 1 & 1 \\
\hline (Goodness) What a surprise! & 1 & 2 & 3 & Nggak disangka nih! & 3 & 1 & 4 \\
\hline I'm really thrilled! & 1 & - & 1 & Alhamdulillah! & 3 & 2 & 5 \\
\hline Well, what exciting things. & 2 & - & 2 & Kapan beritanya? & 1 & 1 & 2 \\
\hline & & & & Asyik! & - & 2 & 2 \\
\hline & & & & Bukan main! & - & 2 & 2 \\
\hline & & & & Wah, tumben! & 2 & 1 & 3 \\
\hline
\end{tabular}

Note: Freq: frequency; F: female; M: male; T: total

As can be seen in Table 3, there were a few phrases which occurred only in expressing enthusiasm but not in expressing surprise. In Australian English, these phrases were such as: "(Wow!) Good news!", "Well, what exciting things", "(Great!), I can't wait (to go). In Bahasa Indonesia, these were: "Nah ini!" or "Nah gitu dong!", "Wah dari dulu dong!", and "Duh! Ini dia yang ditunggu-tunggu". All these expressions shared one pragmatic meaning, that was to indicate one's enthusiastic feeling towards something she/he has been looking forwards to seeing/having/hearing.

Exclamatory expressions of annoyance were interesting to analyze. Again, both languages had different set of words or phrases in expressing this. It appeared that Bahasa Indonesia had more exclamatory words of annoyance than that of Australian English. It can be seen in Table 4 that phrases such as: "Shit!" or "Bulshit!" appeared most frequently in Australian English - most of them 
appeared in males' expressions. such as: "Shit!" or "Bulshit" and "Damn!" or "Damn this (it)!" or "Fuck!" or "Fuck out!". Such "Damnation!", "Hell!" or "Bloody expressions appeared more Hell!", "Fuck!" or "Fuck out!" were frequently in the expressions of also frequent. There was a males of below 25 age category. tendency for males to use words or The following table shows a phrases which were more sensitive detailed description of these words in their meaning and use in or phrases.

society. These expressions were

Table 4

Exclamatory Words or Phrases Used in Expressing Annoyance

\begin{tabular}{|c|c|c|c|c|c|c|c|}
\hline Australian English & & Freg & & Bahasa Indonesia & & Frec & \\
\hline & F: & $\mathrm{M}:$ & & & F: & $M: T$ & \\
\hline Shit! or Bulshit! & 5 & 11 & 16 & Sial(an)! & 6 & 5 & 11 \\
\hline Damn $\quad$ (it) & & & & Brengsek! & 4 & 3 & 7 \\
\hline Damnation! & 7 & 3 & 10 & Dasar! & 4 & 2 & 6 \\
\hline Hell! or Bloody hell! & 4 & 4 & 8 & Keparat! & 1 & 5 & 6 \\
\hline Fuck! or Fuck out! & - & 6 & 6 & Babi (ngepet)! & - & 2 & 2 \\
\hline Christ! & 3 & 2 & 5 & Anjing! & - & 2 & 2 \\
\hline Jesus! & 2 & 2 & 4 & Kapok (aku)! & 2 & 1 & 3 \\
\hline Oh God! & 1 & 2 & 3 & Huh! & 1 & 1 & 2 \\
\hline Ghost! & 1 & 1 & 2 & Bangsat! & - & 2 & 2 \\
\hline Combination & & & & Kurang ajar! & 2 & 2 & 4 \\
\hline Damna & 3 & 2 & 5 & (Wah) Celaka (tiga belas)! & 2 & - & 2 \\
\hline Oh bugger! & & & & Ya Allah! & 3 & 1 & 4 \\
\hline & & & & Kacau nih! & 1 & 1 & 2 \\
\hline & & & & Monyet! & - & 1 & 1 \\
\hline & & & & Setan! & 1 & 2 & 3 \\
\hline & & & & Pantek! & - & 1 & 1 \\
\hline & & & & Penipu! & 1 & 1 & 2 \\
\hline & & & & Sinting! & 1 & - & 1 \\
\hline
\end{tabular}

Note: Freq: frequency; F: female; M: male; T: total

In Bahasa Indonesia, "Sial!" or of these words might be parallel to "Sialan" were most frequent in "Damn" or "Damnation". It expressing annoyance (both appeared that words or phrases males and females). The meaning which refer to the name of animals 
and which remain sensitive in their use and meaning, like "Anjing!" (dog), "Monyet!" (monkey), "Bangsat!" (scoundrel) and "Babi (ngepet)!" (pig), only appeared in males' expressions. At the same time, the word "Keparat!" (swearing word which is identical with "Shit") which was socially insulting and offensive in their use, occurred more frequently in males' expressions than in females'.

There were also words or phrases which referred to the name of God found in the expressions of annoyance in both languages. Obviously, they were not insulting and offensive at all in their use and meaning. They were probably used to release the speaker's stress by referring or saying the name of God. Such expressions were as: "Oh God!" and "Ya Allah!" (Bahasa Indonesia). Another sensitive word which only occurred once in the data is "Pantek". In fact, this word is well known as a very taboo word in Minang society only (people of West Sumatera). However, the use of this word might have spread to other societies in Indonesia. "Pantek" is a word which refers to female genitalia and remains very sensitive, offensive and insulting, especially in Minang society.

\section{CONCLUSION}

The findings revealed that both Australian English and Bahasa Indonesia had different types of exclamatory words, phrases in expressing surprise, enthusiastic and annoyance. They occurred unpredictably but seemed to be systematic in their constructions. The selection of words or phrases in exclamation remained personal and indicated the speakers' feeling, attitude and emotion. In expressing surprise and enthusiasm, in particular, the selection of words or phrases remained positive and socially acceptable in their use. However, in expressing annoyance, most of the words, phrases or expressions used were taboo and socially unacceptable. They have a relatively strong negative connotation and sensitive meaning. It appeared that the younger the 
speakers, the more sensitive the words or phrases selected in expressing annoyance.

\section{REFERENCESS}

Anderson, L. and P. Trudgill. 1990. Bad Language. Basil Blackwell Ltd., Cambridge.

Blum - Kulka, S. et all. 1989. Cross-Cultural Pragmatics. Ablex, Norwood - New York.

Blum - Kulka, S. \& E. Olshtain. 1984. Requests and Apologies; A Cross - Cultural Study of Speech Act Realization Pattern (CCSARP). Journal of Applied Linguistics, 5 (3): 196 212.

Drazdauskiene, M. 1981. "On Stereotypes in Conversation". in Conversational Routine: Explorations in Standardized Communication Situations and Prepatterned Speech. Coulmas (ed.). Mouton, The Hague. (p.55 - 68).

Golato, A. 2003. Studying Compliment Responses: A Comparison of DCTs and Recordings of Naturally Occurring Talk. Applied Linguistics, 24 (1): 90-121.

Kohler, Michael. 2008. Refusals in English and Greek: Theoretical Aspects and
Empirical Study. ZfAL. Vol 48 (pp. 75-104).

LDOTEL. 1984. Longman Dictionary of the English Language. (Heather Gay, Brian O'Kill, Katherine Seed, Janet Whitcut, eds). Longman, London.

Milroy, James and Milroy, Lesley. 1990. Language in Society: Sociolinguistics. In Collinge, N.E. (Ed). Encyclopedia of Language. London: Routledge. (pp.485-517).

Montagu, A. 1967. The Anatomy of Swearing. Rapp \& Whiting, London.

Tran, Giao Quynh. 2008. The Naturalized Role-Play: An Innovative Methodology in Cross-Cultural and Interlanguage Pragmatics Research. Reflection on English Language Teaching, 5 (2): 1-24.

Wardhaugh, R. 1992. An Introduction to Sociolinguistics. 2nd edn. Balckwell, Oxford.

Wierzbicka, Anna. 1991. Cross Cultural Pragmatics; The Semantics of Human Interaction. Mouton de Gruyter, Berlin.

Wouk, F. 2006. The Language of Apologizing in Lombok, Indonesia. Journal of Pragmatics, (38): 1457-1486. 
Adrefiza

Yuan, Y. 2001. An Inquiry into Empirical Pragmatics DataGathering Methods: Written DCTs, Field Notes, and Natural Conversations. Journal of Pragmatics, (33): 271292. 